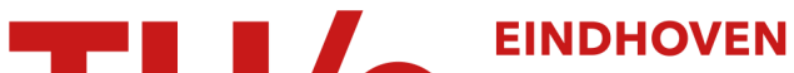 UNIVERSITY OF TECHNOLOGY
}

\section{Dual decision-feedback equalizer with variable detection delay}

Citation for published version (APA):

Bergmans, J. W. M. (2000). Dual decision-feedback equalizer with variable detection delay. Electronics Letters, 36(5), 473-474. https://doi.org/10.1049/el:20000389

DOI:

10.1049/el:20000389

Document status and date:

Published: 01/01/2000

\section{Document Version:}

Publisher's PDF, also known as Version of Record (includes final page, issue and volume numbers)

\section{Please check the document version of this publication:}

- A submitted manuscript is the version of the article upon submission and before peer-review. There can be important differences between the submitted version and the official published version of record. People interested in the research are advised to contact the author for the final version of the publication, or visit the $\mathrm{DOI}$ to the publisher's website.

- The final author version and the galley proof are versions of the publication after peer review.

- The final published version features the final layout of the paper including the volume, issue and page numbers.

Link to publication

\section{General rights}

Copyright and moral rights for the publications made accessible in the public portal are retained by the authors and/or other copyright owners and it is a condition of accessing publications that users recognise and abide by the legal requirements associated with these rights.

- Users may download and print one copy of any publication from the public portal for the purpose of private study or research.

- You may not further distribute the material or use it for any profit-making activity or commercial gain

- You may freely distribute the URL identifying the publication in the public portal.

If the publication is distributed under the terms of Article $25 \mathrm{fa}$ of the Dutch Copyright Act, indicated by the "Taverne" license above, please follow below link for the End User Agreement:

www.tue.nl/taverne

Take down policy

If you believe that this document breaches copyright please contact us at:

openaccess@tue.nl

providing details and we will investigate your claim. 


\section{Dual decision-feedback equaliser with variable detection delay}

\section{J.W.M. Bergmans}

The use of a variable detection delay is proposed to improve the bit error rate and error propagation characteristics of a dual decision-feedback equaliser.

Decision-feedback equaliser: Digital transmission and recording systems often employ feedback-type detectors such as the decisionfeedback equaliser (DFE) [1], fixed-delay tree search with decision feedback (FDTS/DF) [2], and the dual DFE (DDFE) [3]. Among these detectors, the DDFE stands out because it achieves close-tooptimum performance while having a remarkably low complexity. The performance of the DDFE depends on its detection delay, which in the basic DDFE is fixed and determined by two internal shift registers. In this Letter the use of a variable detection delay is proposed as a means for improving the bit error rate and error propagation characteristics of the DDFE.
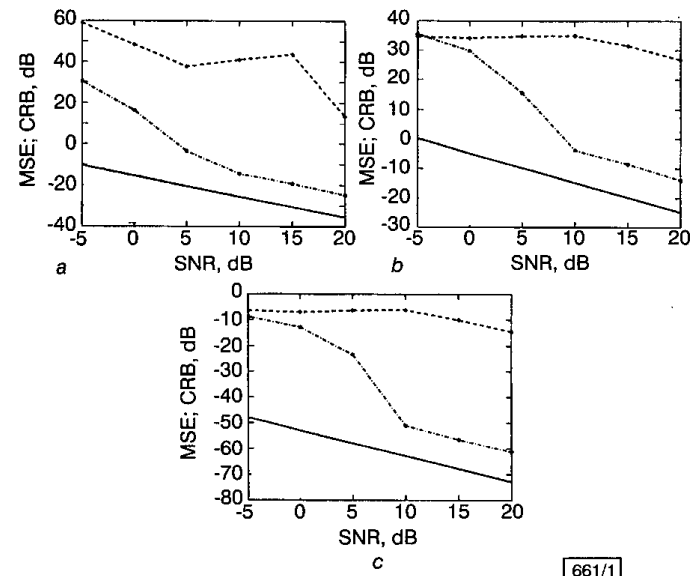

Fig. 1 Baseline system with decision feedback equaliser (DFE)

We first present some DFE basics. The replay signal $r(t)$ in Fig. 1 is a linearly distorted and noisy version of the transmitted data sequence $a_{k}$ of data rate $1 / T$. The function $h(t)$ represents the response of the system to a single transmitted bit. Noise $n(t)$ may or may not be white. The forward filter in Fig. 1 has impulse response $w(t)$. It serves to suppress precursive intersymbol interference (ISI) at the decision instants $t_{k}=k T$, to reject out-of-band noise, and to whiten in-band noise. Ideally the equalised and sampled system response $q_{k} \triangleq\left(h^{*} w\right)(k T)$ is a minimum-phase function so that a maximum fraction of the energy of $q_{k}$ is concentrated near the time origin $(k=0)$. Minimum-phase functions are all causal $\left(q_{k}=0\right.$ for $\left.k<0\right)$, i.e. precursive ISI is indeed absent. Without loss of generality we may set $q_{0}=1$. Post-cursive ISI is due to the 'tail' $q_{1}, q_{2}, \ldots$ of $q_{k}$. This tail serves as the impulse response of a feedback filter (FBF) that is excited by past decisions $\hat{a}_{k-1}, \hat{a}_{k-2}, \ldots$ The FBF output is subtracted from the forward filter output so as to cancel post-cursive ISI. If past decisions affecting the FBF output are all correct then the decision variable $\tilde{a}_{k}$ is just a noisy version of $a_{k}$, and a new bit-decision $\hat{a}_{k}$ can be formed by means of a slicer with zero threshold. The difference $e_{k}$ $=\tilde{a}_{k}-\hat{a}_{k}$ is a measure of the decision quality, and is commonly used to drive the read-path control loops.

Dual DFE: The DFE is suboptimum because it exploits only the cursor $q_{0}$ in the detection process. Error propagation constitutes a second (and typically much smaller) loss factor. The DDFE represents an improvement on the DFE in both respects (Fig. 2). It uses two DFEs that run independently of each other and most of the time deliver the same decisions. Both DFEs are identical except that the threshold levels of their bit-detectors have antisymmetric offsets $\pm \alpha$ where $\alpha \approx 0.2-0.3$. Most of the time, noise is small and the decisions $\hat{a}_{k}^{1}$ and $\hat{a}_{k}^{2}$ of both DFEs are correct and identical. Occasionally, however, the decision variables $\tilde{a}_{k}^{1}$ and $\tilde{a}_{k}^{2}$ of the DFEs fall within the erasure zone $[-\alpha, \alpha]$. In this event the decisions are uncertain and are, moreover, different. Since both decisions are applied to a shift register with $\delta$ stages, the detector can permit itself a total of $\delta$ symbol intervals to determine which of both DFE outputs to settle on. Throughout this erasure period detection thresholds are zeroed so as to maximise the probability that subsequent DFE decisions will be correct. The DFE with the correct decision $\hat{a}_{k}$ is likely to produce small error samples $e_{k}=\tilde{a}_{k}$ $-\hat{a}_{k}$ in the remainder of the erasure period, while the error samples of the other DFE are likely to be relatively large because the erroneous decision causes imperfect cancellation of trailing ISI. A comparison of the energy of both errors across the erasure period is used to select between both DFEs. The switch in Fig. 2 is set accordingly, and both DFEs are realigned by transferring the register contents of the 'selected' DFE to the other one. Detection thresholds then re-assume their default values $\pm \alpha$, and erasure detection recommences.

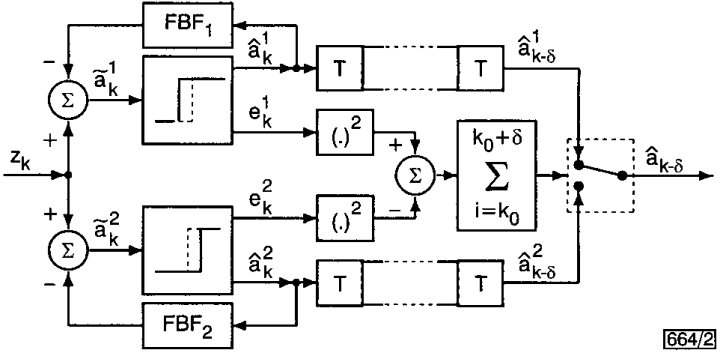

Fig. 2 Schematic model of DDFE

Control logic not shown

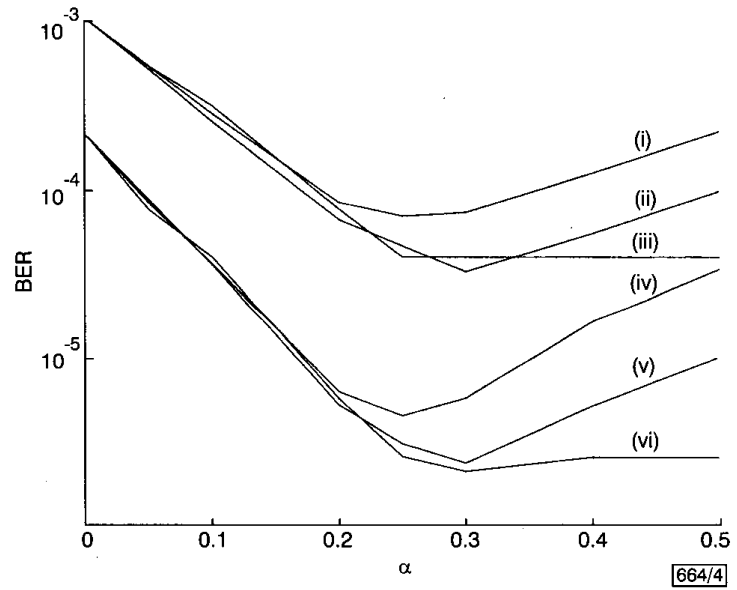

Fig. 3 Bit error rate against erasure threshold $\alpha$ for various values of $D$ at normalised information density $t_{50} / T=2.85$

(i) $\mathrm{SNR}=15 \mathrm{~dB}$, fixed delay

(ii) $\mathrm{SNR}=15 \mathrm{~dB}, D=3$

(iii) $\mathrm{SNR}=15 \mathrm{~dB}, D=1.5$

(iv) $\mathrm{SNR}=16 \mathrm{~dB}$, fixed delay

(v) $\mathrm{SNR}=16 \mathrm{~dB}, D=3$

(vi) $\mathrm{SNR}=16 \mathrm{~dB}, D=1.5$

The performance of the DDFE is basically equal to that of near-optimum restricted-delay schemes such as FDTS/DF [3]. The complexity, however, is much lower. Bursts of errors tend to be shorter than for the DFE. Erasures occur much more frequently than bit errors and can be counted to obtain an accurate prediction of the bit error rate.

Variable detection delay: In the basic scheme of Fig. 2, the DDFE has a fixed detection delay of $\delta$ symbol intervals. For $\delta=0$ the DDFE degenerates into a DFE. As $\delta$ is increased beyond this point, the performance initially improves rapidly because the DDFE exploits an increasing fraction of 'useful' data energy (namely the energy that stems from the 'tail' $q_{1}, q_{2}, \ldots$ of $q_{k}$ ). Once this tail is covered, the performance gradually declines because the DDFE dwells during an increasing fraction of the time within the 
erasure periods. Throughout these periods it effectively functions as a DFE, and as $\delta \rightarrow \infty$ its net performance again approaches that of the DFE.

The basic insight into the use of a variable detection delay is that most DDFE decisions can be reliably made shortly after the beginning of an erasure period. More specifically, if the erasure period commences at the instant $k=k_{0}$ and if $d_{n}$ denotes the accumulated error-energy-difference between the two DFEs from the start of the erasure period (i.e. $\left.d_{n} \triangleq \Sigma_{i=k}^{k_{0}+n}\left(\epsilon_{i}^{1}\right)^{2}-\left(e_{i}^{2}\right)^{2}\right)$, then a large positive value of $d_{n}$ indicates that decisions $\hat{a}_{k}^{2}$ are much more likely than $\hat{a}_{k}^{1}$, and vice versa for a large negative value. This suggests that we end the erasure period as scon as $\left|d_{n}\right|$ exceeds a prescribed reliability threshold $D$, and no later than $\delta$ symbol intervals after the commencement of the erasure period (i.e. no later than for $n=\delta$ ). In all cases the final DDFE decision is based on the sign of $d_{n}$ at the end of the erasure period. Both DFEs are then realigned, and erasure thresholds re-assume their default values $\pm \alpha$.

In many cases $\left|d_{n}\right|$ will cross the reliability threshold $D$ within a few symbol intervals from the beginning of the erasure period, so that the average detection delay $\delta$ will be strictly smaller than the maximum delay $\delta$. Clearly $\bar{\delta}$ is a monotonically increasing function of $D$, ranging between 0 for $D=0$ and $\bar{\delta}=\delta$ for $D=\infty$. As a rule of thumb, if the bulk of the energy of the system response $q_{k}$ is contained within the first $M$ samples, then $D$ should be selected in order for $\bar{\delta}$ to be somewhat larger than $M$.

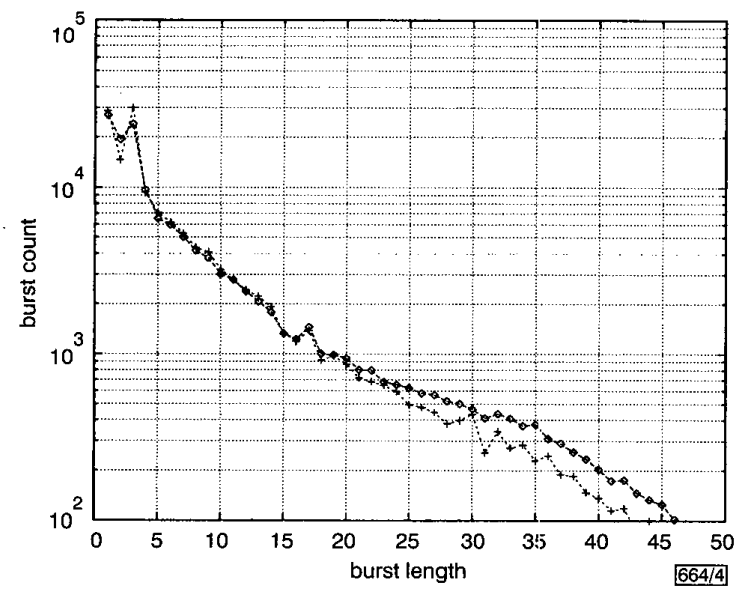

Fig. 4 Burst-error statistics for DDFE with fixed! detection delay and one with variable detection delay at normalised injormation density $t_{50}$ $T=2.85$ and channel signal-to-noise ratio of $15 \mathrm{dE}$

Both curves correspond to total of $5 \times 10^{5}$ bit errors

$\diamond$ fixed detection delay $(\alpha=0.25, \delta=8)$

+ variable detection delay $(\alpha=0.3, \delta=8, D=2$ )

Simulation results: Fig. 3 depicts the impact of a variable detection delay on the bit error rate for a Lorentzian digital magnetic recording channel according to [1], at normalised information density $t_{50} / T=2.85$. Data $a_{k}$ are uncoded, and the noise is Gaussian and white. The DDFE has $\delta=8$. For a fixed detection delay (corresponding to $D=\infty$ ), the bit error rate is smallest for $\alpha \simeq 0.25$. As $D$ decreases, this minimum shifts to somewhat higher values of $\alpha$, and the bit error rate becomes significantly less sensitive to variations of $\alpha$ beyond $\alpha \simeq 0.25$. This reduced sensitivity is desirable for implementation reasons, and helps to improve the bit error rate estimation.

A value $D$ of the order of 1.5 is close to optimum for the system at hand, and leads to average detection delays of the order of two symbol intervals. The minimum bit error rate for $D=1.5$ is a factor of 2-3 better than for a fixed detection delay $(D=\infty)$. This corresponds to an improvement in the predetection signal to noise ratio of $\sim 0.2-0.3 \mathrm{~dB}$. Long bursts of errors also become less likely (Fig. 4).

If $\left|d_{n}\right|$ is still below the reliability threshold $D$ (or below a prescribed fraction of $D$ ) for $n=\delta$ then the resulting final DDFE decision can be deemed unreliable. A flag can then be sent to the error correction procedure so as to facilitate and improve this procedure.
In the histogram of Fig. 4 it can be observed that the proposed technique reduces the amount of double bit errors and increases the proportion of triple bit-errors. This change reflects the fact that the dominant failure mechanisms of the detector have shifted towards those of an optimum restricted-delay detector. A direct implication is that coding techniques that are tailored to this type of detector, such as those of [4], will be of greater interest to the DDFE with variable detection delay than to a DDFE with a fixed delay.

(C) IEE 2000

Electronics Letters Online No: 20000389

17 January 2000 DOI: 10.1049/el:20000389

J.W.M. Bergmans (Philips Research Laboratories, Prof. Holstlaan 4 5656 AA Eindhoven, The Netherlands)

J.W.M. Bergmans: Now with Eindhoven University of Technology, PO Box 513, 5600 MB Eindhoven, The Netherlands

E-mail: J.W.M.Bergmans@tue.nl

\section{References}

1 BERGMANS, J.W.M.: 'Digital baseband transmission and recording' (Kluwer Academic Publishers, 1996)

2 MOON, J., and CARLEY, L.R.: 'Performance comparison of detection methods in magnetic recording', IEEE Trans., 1990, MAG-26, pp. 3155-3172

3 BERGMANS, J.W.M., VOORMAN, J.O., and WONG-LAM, H.W.: 'Dual decision feedback equalizer', IEEE Trans., 1997, COM-45, pp. 514-518

4 MOON, J., and BRICKNER, B.: 'Maximum transition run codes for data storage systems', IEEE Trans., 1996, MAG-32, pp. 3992-3994

\section{Fast computation of discrete $\mathrm{W}$ transform through discrete Hartley transform (DHT)}

\section{L.Z. Cheng}

A new algorithm is presented for the type-II, -III and -IV discrete $\mathrm{W}$ transforms which involves the simple conversion of a length- $N$ discrete $\mathrm{W}$ transform into a length- $N$ discrete Hartley transform. The total number of additional arithmetic operations introduced by the conversion is less than $5 N$.

Introduction: As a generalisation of the discrete Hartley transform (DHT), the discrete W transform (DWT) has become a useful tool in signal processing $[1-3]$. The development of fast algorithms for performing DWTs is, therefore, an active area of research. To represent the fast algorithm for the DWT, we restate the definition of the type-I, -II, -III and -IV DWTs of a real-valued sequence $x(n)$ as follows:

$$
\begin{gathered}
X_{I}(k)=\sum_{n=0}^{N-1} x(n) \operatorname{cas} \frac{2 n k \pi}{N} \\
X_{I I}(k)=\sum_{n=0}^{N-1} x(n) \operatorname{cas} \frac{n(2 k+1) \pi}{N} \\
X_{I I I}(k)=\sum_{n=0}^{N-1} x(n) \operatorname{cas} \frac{(2 n+1) k \pi}{N} \\
X_{I V}(k)=\sum_{n=0}^{N-1} x(n) \operatorname{cas} \frac{(2 n+1)(2 k+1) \pi}{2 N}
\end{gathered}
$$

where $\operatorname{cas}(z)=\cos (z)+\sin (z), k=0,1, \ldots, N-1$, and subscripts $I$, $I I, I I I$ and $I V$ indicate the type-I, -II, -III and -IV DWTs, denoted by DWT-I, -II, -III and -IV, respectively. Obviously, DWT-I is just the discrete Hartley transform (DHT [4-6]). To coincide with the usually used notation, in this Letter DWT-I is still referred to as DHT

Both the fast cosine transform (FCT) algorithm for the DWTs developed by Wang [1] and the fast polynomial transform (FPT) algorithm for the multi-dimensional DWT reported by Zeng [2] require the transform lengths to be a power of 2 . Whereas with 